\title{
Reflexões sobre o ensino de Geografia em Goiás a partir da introdução da Base Nacional Comum Curricular
}

\author{
Reflections on the teaching of Geography in Goiás from the introduction of the Common Base \\ National Curriculum
}

\begin{abstract}
Réflexions sur l'enseignement de la géographie à Goiás depuis l'introduction du curriculum national de la base commune
\end{abstract}

Leovan Alves dos Santos ${ }^{1}$

Secretaria Estadual de Educação de Goiás Seduc/GO

\begin{abstract}
Resumo: Nesse trabalho discute-se a proposta de ensino de Geografia presente nos documentos que orientam as propostas curriculares em Goiás para o Ensino Fundamental e para o Ensino Médio. Busca-se o entendimento de como fica o ensino de Geografia a partir da criação da BNCC? Quais as possibilidades do professor de Geografia para o desenvolvimento de sua atividade docente a partir da BNCC? Quais as possibilidades para o trabalho do professor de Geografia em Goiás frente ao DC Goiás? Realizou-se uma análise documental e bibliográfica, por meio das quais destacou-se o trabalho do professor de Geografia frente aos limites e possibilidades presentes nestes documentos. Ressalta-se que é no trabalho do professor que temas e conteúdos são desenvolvidos em sala de aula buscando-se a construção do pensamento geográfico.
\end{abstract}

Palavras-chave: BNCC. Políticas curriculares. DC Goiás. Ensino de Geografia.

Abstract: This work discusses the proposal for teaching Geography present in the documents that guide curriculum proposals in Goiás for elementary and high school. Are you looking for an understanding of how Geography teaching looks after the creation of BNCC? What are the possibilities of the Geography teacher for the development of his teaching activity from the BNCC? What are the possibilities for the work of the Geography teacher in Goiás compared to DC Goiás? A documentary and bibliographic analysis was carried out, highlighting the work of the Geography teacher in view of the limits and possibilities present in these documents. It is emphasized that it is in the teacher's work that themes and contents are worked on in the classroom, seeking to build geographic thinking.

Keywords: BNCC. Curriculum Policies. DC Goiás. Geography teaching.

Résumé: Dans ce travail, la proposition d'enseignement de la géographie est discutée dans les documents qui guident les propositions curriculaires à Goiás pour le primaire et le secondaire. Vous cherchez à comprendre comment l'enseignement de la géographie suit la création du BNCC? Quelles sont les possibilités du professeur de géographie pour le développement de son activité d'enseignement au BNCC? Quelles sont les possibilités pour le travail du professeur de géographie à Goiás par rapport à DC Goiás? Une analyse documentaire et bibliographique a été réalisée, mettant en évidence le travail du professeur de Géographie au regard des limites et des possibilités présentes dans ces documents. Il est souligné que c'est

\footnotetext{
${ }^{1}$ Doutorando em Geografia pela Universidade Federal de Goiás. Professor das redes de ensino do município de Goiânia e da rede Estadual de Goiás. E-mail: leovanalves@yahoo.com.br ORCID: https://orcid.org/0000-00019918-5006. Lattes: http://lattes.cnpq.br/4419799115373100.
} 
dans le travail de l'enseignant que les thèmes et les contenus sont travaillés en classe, en cherchant à construire une réflexion géographique.

Mots-clés: BNCC. Politiques du curriculum. DC Goiás. Enseignement de la géographie.

Recebido em: 12 de abril de 2019 Aceito em: 17 de janeiro 2020

\section{Introdução}

Em abril de 2017, o Ministério da Educação (MEC) entregou ao Conselho Nacional de Educação (CNE) uma Base Nacional Comum Curricular (BNCC), que contempla a Educação Infantil e o Ensino Fundamental. A BNCC referente ao Ensino Médio não acompanhou esse processo de discussão devido às alterações que vieram a partir da Lei $n^{\circ}$ 13.415/2017 (BRASIL, 2017) e trouxeram novas definições para esse nível de ensino.

As discussões que envolveram a construção da BNCC tiveram início em 2012, quando as primeiras críticas em relação aos procedimentos de construção do documento começaram a ganhar visibilidade por meio de publicações acadêmicas. Desde então, entrou, na agenda do país, a elaboração de uma BNCC para reger a estrutura dos componentes curriculares da Educação Básica nacional em suas diferentes etapas. A versão final homologada pelo CNE em dezembro de 2017 sinalizou principalmente três mudanças no campo educacional:

- A primeira mudança ocorreu na formação de professores, que passou a ser pautada e orientada pela BNCC na formação inicial ou continuada.

- A segunda mudança ocorreu nos editais de compra de material didático. A Base tornou-se a orientadora dos currículos estaduais e, com isso, o Programa Nacional do Livro e do Material Didático (PNLD), nos editais de compra de livros dos programas de 2019 e 2020, já incluiu, como critério de seleção, a adequação e o alinhamento à BNCC.

- Uma terceira mudança diz respeito às avaliações externas: a Educação Infantil será avaliada, a partir de 2019, por meio do Sistema de Avaliação da Educação Básica (Saeb). A BNCC homologada também apresentou prazos para que o Instituto Nacional de Estudos e Pesquisas Educacionais Anísio Teixeira (Inep) revise suas matrizes.

Diante dessas modificações, busca-se aqui o entendimento de como fica o ensino de Geografia, na Educação Básica a partir da criação da BNCC? Quais as possibilidades do professor de Geografia na escola básica para o desenvolvimento de sua atividade docente a partir da BNCC? Quais as possibilidades para o trabalho do professor de Geografia em Goiás frente ao documento curricular (DC Goiás) construído a partir da BNCC? 
Objetiva-se nesse trabalho analisar limites e possibilidades para o trabalho do professor de Geografia a partir da introdução do DC Goiás (GOIÁS, 2018) advindo da BNCC (BRASIL, 2018). Para isso, realizou-se uma análise nesses documentos refletindo-se sobre a proposta de ensino de Geografia para os anos finais do Ensino Fundamental e para a etapa do Ensino Médio.

Realizou-se também, uma análise bibliográfica em trabalhos desenvolvidos por Cury, Reis e Zanardi (2018) e Camilo Costa, Rodrigues e Stribel (2019) que apresentam importantes análises sobre o processo de construção e implementação da BNCC na Educação Básica; e nos trabalhos de Callai (2013), Castellar (2019), Cavalcanti (2019) que apresentam importantes elementos para pensar o papel dos conteúdos e a formação de conceitos no ensino de Geografia.

O DC-GO (GOIÁS, 2018), alicerçado na BNCC, evidencia os conhecimentos essenciais que todos os estudantes goianos têm o direito (e de certa forma uma obrigação) de ter acesso durante sua trajetória na Educação Básica, ano a ano, desde o ingresso na creche até o final do Ensino Fundamental. Com esse documento, a partir do ano letivo de 2019, as secretarias estaduais e municipais, as redes particulares, as escolas e os professores iniciaram um novo instrumento de gestão e controle do trabalho pedagógico. Vale ressaltar que o DC Goiás Ensino Médio ainda está em construção (já está em sua versão preliminar) devido ao atraso na homologação da BNCC referente a essa etapa da Educação Básica.

A partir de 2019 a BNCC começou a ser implantada em Goiás especialmente nos anos iniciais do Ensino Fundamental, uma vez que o DC-GO começou sua implantação por essa fase focando principalmente na formação dos professores. Além disso, os livros didáticos que chegaram às escolas já trouxeram sistematicamente todas as competências e as habilidades do documento. Diante deste cenário, de uma anunciada mudança curricular no estado, centra-se a análise e reflexão aqui proposta.

\section{Elementos iniciais da inserção da BNCC em Goiás}

A construção da BNCC nasce como uma proposta de avanço na educação brasileira e tem como finalidade orientar os sistemas na elaboração das suas propostas curriculares. O mesmo traz também como seu principal fundamento o direito a aprendizagem e desenvolvimento, seguindo uma perspectiva inclusiva do aprender e do desenvolvimento integral do estudante.

Cury, Reis e Zanardi (2018) destacam que a BNCC carrega em si o sonho de universalização de direitos no que diz respeito ao acesso do conhecimento acumulado e à qualidade da educação que se realizaria pela distribuição igualitária e isonômica desses conhecimentos. Dessa forma, os autores destacam que a escolha de uma BNCC, seja no plano normativo, seja no plano conceitual, nos leva a compreender a proposta de orientação curricular nacional: 
A BNCC seria o instrumento para qualificar a educação através de uma identidade de conhecimentos que seja proporcionada a todos os estudantes da Educação Básica brasileira. Ela serviria para superar as desigualdades evidentes em nosso sistema educacional. Ela se envolve em uma visão de escolarização que, para termos uma educação de qualidade seria necessário proporcionar conteúdos idênticos para possibilitar uma igualdade de oportunidade entre os educandos. (CURY; REIS; ZANARDI, 2018, p. 61).

Os defensores da BNCC entendem que uma das mazelas da educação brasileira a ser superada é a ausência de um conteúdo básico e comum em todo o país, e, com a BNCC, foi apresentada uma possibilidade de superar as desigualdades e a qualidade deficiente da educação. Lopes (2017) destaca que a história do currículo é marcada pela ideia de que possa existir uma base nacional que sustente as decisões sobre os saberes e as atividades de ensino, seja ela em função de princípios epistemológicos, psicológicos ou mesmo emancipatórios.

Dessa forma, são escritos parâmetros, diretrizes, orientações e propostas que vão sendo cada vez mais detalhados, tentando tornar mais explícitos os conteúdos a serem formados e as atividades escolares a serem realizadas. São instituídos exames, são estabelecidos controles dos projetos estaduais, municipais e escolares, todo um esforço é dirigido, segundo Lopes (2017), à tentativa de controlar o que não pode ser controlado.

Lopes (2017) defende que não haverá apenas um currículo plenamente produzido numa dada direção, seja ela qual for. Sempre haverá diferentes discursos - mercado, emancipação, cidadania, mundo em mudança, qualidade de ensino, adequação à globalização, saberes universais, conteúdos básicos, justiça social, igualdade, diferença - que estarão disputando a significação do que vem a ser currículo e produzindo significações imprevistas. Nessa perspectiva, de acordo com a autora, uma base curricular comum nacional nunca será instituída de fato e todo o investimento financeiro, subsidiado por acordos internacionais e nacionais, dirigidos para viabilizar essa tentativa, poderia ser direcionado para outras ações educacionais.

Cury, Reis e Zanardi (2018) apontam que a BNCC se constitui como um projeto normativo que estabelece um documento prescritivo de competências, habilidades, conteúdos, ou, como é denominado no documento, de direitos de aprendizagem. Nesse sentido, a Base serve como referência para a construção e a adaptação dos currículos de todas as redes de ensino do país. As redes e as escolas seguem com relativa autonomia para elaborar, por meio do currículo, metodologias de ensino, abordagens pedagógicas e avaliações, incluindo elementos da diversidade local e apontando como os temas e as disciplinas se relacionam. De acordo com a visão oficial, a BNCC e os currículos têm, portanto, papéis complementares: a Base dá o rumo da educação, mostrando aonde se quer chegar, e os currículos traçam os caminhos. 
Seguindo essa lógica, em Goiás, foi homologado no final de 2018 o DC Goiás (GOIÁS, 2018) da Educação Infantil e do Ensino Fundamental, que resulta de uma ação impulsionada pela União dos Dirigentes Municipais de Educação de Goiás (Undime-Go), que envolveu diversas frentes de estudo e investigação, com professores da Educação Básica e do Ensino Superior das redes públicas e de instituições particulares, para a implantação da BNCC no estado. A BNCC foi a referência nacional obrigatória para a construção do documento.

Para o Ministério da Educação (MEC), a (re)elaboração se refere "ao processo de tradução da BNCC em um documento curricular local e contempla tanto as redes que farão a sua primeira elaboração curricular, quanto as redes que já possuem currículo e farão uma atualização alinhada à BNCC” (BRASIL, 2018, p. 06).

Ao assegurar um conjunto de conhecimento e fazeres advindos da BNCC, o DC-GO traz como discurso a possibilidade de diminuir as desigualdades relacionadas à aprendizagem, colaborando para a construção de uma sociedade mais justa e igualitária em termos de acesso e permanência dos estudantes nas escolas. Camilo Costa, Rodrigues e Stribel (2019) apresentam críticas a essa forma de pensar a construção curricular e destacam que:

A estrutura apresentada no documento da BNCC (BRASIL, 2018) ajuda a questionar sua construção, uma vez que tende a facilitar uma compatibilização com instrumentos de regulação de avaliações externas, tais como o Programa Internacional de Avaliação de Estudantes (PISA Programme for International Student), a Prova Brasil (Avaliação Nacional do Rendimento Escolar, integra o Sistema Nacional de Avaliação da Educação Básica - SAEB) ou a Avaliação Nacional da Alfabetização (ANA - que também integra o SAEB), sobretudo com a codificação de cada habilidade que ela propõe. Este é um dos principais diferenciadores entre a BNCC e outros documentos curriculares anteriores. A BNCC é construída com objetivos e habilidades apresentados de maneira definida, visando precisão, o que supõe pouca margem a variações, reitera o controle, como adverte Lopes (2015). Com isso, o documento delineia leituras curriculares aproximadas de abordagens como as de Ralph Tyler, Benjamin Bloom e Robert Mager (PINAR, 2007; LOPES; MACEDO, 2011), por exemplo, cujas contribuições ao pensamento curricular assinalam o que podemos pensar como movimento eficientista comportamentalista, baseado na definição de objetivos, em uma dimensão de gestão anterior à escola, que teria na avaliação um mecanismo de controle sobre a execução e aquisição dos objetivos pretendidos (CAMILO COSTA, RODRIGUES, E STRIBEL, 2019, p. 96-97).

As críticas apresentadas por Camilo Costa, Rodrigues, e Stribel (2019) relaciona-se ao controle presente na BNCC que pode restringir as possibilidades de diálogo, favorecendo a manutenção do status quo, além de operar na redução da escola a formas de reprodução da sociedade classista e negligenciar o que é produzido no âmbito da escola, por professores, estudantes e comunidades. 
Cury, Reis e Zanardi (2018) apontam que a BNCC traz uma concepção de currículo travestida de direitos de aprendizagem que, sob a ótica tecnicista e meritocrática, constituemse em deveres de aprendizagem. Nessa perspectiva, não é possível negar a natureza curricular da BNCC simplesmente porque ela rejeita tal concepção. Paradoxalmente, os enunciados expostos desafiam a concepção da BNCC, que se recusa a assumir que deseja estabelecer o que os alunos devem estudar.

Quando se analisa os encaminhamentos que já estão sendo postos em prática, como, por exemplo, a construção do DC-GO, é possível perceber a natureza curricular da BNCC. O DC-GO foi produzido para organizar os direitos (deveres) de aprendizagens, conhecimentos e habilidades com foco na competência compreendida como a mobilização de conhecimentos (conceitos e procedimentos).

Cury, Reis e Zanardi (2018) ressaltam que a própria BNCC assume que a função das competências é orientar os currículos, ou seja, é a fonte de todos os currículos, que não se orientariam mais por objetivos. Por mais que se busque fugir da seleção, da organização e do sequenciamento de conteúdos, a BNCC tem esse papel e ela não pode deixar de ser considerada como um currículo prescrito.

Assim, a BNCC e os demais currículos advindos a partir dela (tal qual o DC Goiás) têm papéis complementares para assegurar as aprendizagens essenciais definidas para cada etapa da Educação Básica, uma vez que tais aprendizagens só se materializam mediante o conjunto de decisões que caracterizam o currículo em ação.

\section{A proposta de ensino de Geografia no DC Goiás para o Ensino Fundamental}

O ensino de Geografia na escola deve ser realizado de acordo com Cavalcanti (2019) de modo que seja significativo para os estudantes. Define-se como meta o trabalho com o conteúdo geográfico com vistas a formação de um modo de pensar a realidade, um modo de se pensar geograficamente. Nesse entendimento, o espaço geográfico é o objeto central de estudo, os conceitos território, paisagem, natureza, lugar e região são abordados, por sua vez, como estruturantes no trabalho com as diferentes situações geográficas.

Ao longo da BNCC (BRASIL, 2018) a Geografia se estabelece como uma oportunidade para compreensão do mundo atual e, para tal objetivo, o documento também lança mão das categorias analíticas dessa ciência. Ressalta-se na BNCC a necessidade de que os estudantes ampliem seus conhecimentos sobre o uso do espaço em diferentes situações geográficas regidas por normas e leis historicamente instituídas, compreendendo a transformação do espaço em território usado 
(SANTOS, 2000) - espaço da ação concreta e das relações desiguais de poder, considerando também o espaço virtual proporcionado pela rede mundial de computadores e das geotecnologias.

Castellar (2019) destaca que a Geografia nos coloca diante das escalas geográficas e cartográficas, para entendermos os processos que conduzem às mudanças dos lugares, observando-os e raciocinando sobre eles, estimulando operações lógicas superiores tais como: sequenciar, ordenar, compreender, explicar, estabelecer conexões racionais sobre fatos e fenômenos, a razão da distribuição dos objetos técnicos que compõe a totalidade do espaço geográfico, entre outras, por meio da linguagem cartográfica e de outros tipos de representações. Castellar (2019, p. 16) acrescenta ainda que:

Explicar, por meio de diferentes linguagens e representações, porquê as ocupações de populações tolhidas de seus direitos de habitar a cidade se dão, muitas vezes, em solos de alta erodibilidade, de vertentes exageradamente declivosas ou às margens de córregos canalizados e poluídos? Quais e como as conexões entre os complexos sistemas atmosféricos, litosféricos, hidrológicos, biológicos, políticos, econômicos e culturais, no espaço e no tempo, formam a síntese da vida das pessoas? E por que as vidas das pessoas, suas realidades, são como são e estão onde estão? A Geografia é a síntese das condições das vidas dos sujeitos? Seria esse o poder do conhecimento geográfico?

Todos esses entendimentos expressam de acordo com Cavalcanti (2019) um entendimento da Geografia Escolar, constituída por um conjunto de saberes, internalizados e amalgamados pelo professor, originados em diferentes campos do conhecimento e em diferentes dimensões da prática, e nesse sentido, a Geografia serve par desenvolver o pensamento geográfico.

No DC-Goiás (GOIÁS, 2018), o componente Geografia tem o objetivo de possibilitar a compreensão do espaço geográfico, propondo aos estudantes pensar, ler e observar a ação humana nos espaços, tanto nas áreas rurais como nas urbanas, nos seus espaços de vivências e em outros mais amplos e complexos, abarcando sempre a relação sujeito e espaço e compreendendo esta relação a partir das especificidades de Goiás e na sua relação com o mundo. Nessa perspectiva, o trabalho com o conhecimento geográfico deve ser realizado a partir das três funções essenciais, a seguir, que devem ser desenvolvidas com todos os estudantes:

- A primeira função é uma forma própria de pensar espacialmente;

- A segunda é o desenvolvimento do raciocínio geográfico;

- E a terceira é o aumento da sua capacidade de ler e interpretar o mundo, em todas as suas escalas: local, regional, nacional ou mundial.

Castellar (2019) ressalta que estabelecer ligações entre os problemas postos na vida de cada um com a teoria geográfica é o desafio maior para um professor, pois depende de sua vida 
intelectual, do movimento incessante de procurar reconstruir conceitos e definições sobre objetos, fatos e fenômenos.

Para que os estudantes desenvolvam essas três funções essenciais, o DC Goiás (GOIÁS, 2018) traz princípios geográficos que devem ser exercitados no ensino de Geografia em todos os anos do Ensino Fundamental, sendo eles: "analogia, conexão, diferenciação, distribuição, extensão, localização e ordem”, sendo esses os princípios estabelecidos na BNCC (BRASIL, 2018). Esses princípios se tornam essenciais para que os estudantes possam ter a compreensão dos diversos fenômenos espaciais (naturais e antrópicos), assim como, desenvolver a observação, a interpretação e a análise crítica da ação humana sobre estes espaços modificados.

Os princípios geográficos estão presentes nas competências gerais e na competências específicas do componente curricular Geografia e estabelecem as finalidades gerais ou básicas do ensino e a mobilização de conhecimentos (conceitos e procedimentos), habilidades (práticas, cognitivas e socioemocionais), atitudes e valores para resolver demandas complexas da vida cotidiana e do pleno exercício da cidadania bem como do mundo do trabalho (BRASIL, 2018).

Essa é uma das grandes contribuições da Geografia e que estão demarcadas no DC Goiás: desenvolver o pensamento geográfico, estimulando o raciocínio geográfico para representar e interpretar o mundo em permanente transformação e relacionando componentes da sociedade e da natureza. Para tanto, é necessário que o estudante se aproprie dos conceitos específicos da ciência geográfica para o exercício da cidadania.

Dessa forma, é preciso superar a aprendizagem com base apenas na descrição de informações e fatos do dia a dia, cujo significado restringe-se apenas ao contex to imediato da vida dos sujeitos. A superação dessa condição meramente descritiva exige o domínio de conceitos e generalizações. Estes permitem novas formas de ver o mundo e compreender, de maneira ampla e crítica, as múltiplas relações que conformam a realidade, de acordo com o aprendizado do conhecimento da ciência geográfica. Cavalcanti (2019, p. 104-105) acrescenta que:

No mundo atual, a escala global tem mais peso, está mais forte e é acentuada frequentemente nas análises, mas é preciso observar que o global é uma noção abstrata, é mais um conceito que uma evidência empírica. Ou seja, não há o global na experiência imediata, mas o que faz algo ser considerado global são as suas conexões em diferentes escalas. A escala está, assim, articulada a outro princípio geográfico: o da conexão, em diferentes redes de atuação e repercussão dos fenômenos. Essas redes se complexificaram enormemente nas últimas décadas, quando os avanços referentes aos âmbitos da informação e comunicação passaram a ser uma forte realidade.

Cavalcanti (2019) ressalta a importância de se considerar, no tratamento didático dos conteúdos geográficos, os conhecimentos cotidianos dos alunos, aqueles que são adquiridos em sua prática cotidiana, tendo assim seu lugar como escala de análise dos fenômenos e processos 
estudados. A seleção de conteúdos não deve ser apenas um modo de aprender Geografia, mas aprender, por meio do conhecimento geográfico, o mundo que podemos construir.

Outro aspecto a ser destacado no DC Goiás refere-se à organização por unidades temáticas e objetos de conhecimento que possibilitam um planejamento articulado de diferentes conceitos, procedimentos, atitudes e valores para cada série do Ensino Fundamental. As habilidades desenvolvidas no DC Goiás, por sua vez, constituem caminhos para articular os conceitos com os objetos de conhecimentos, pois sem essa articulação os conceitos seriam apenas definições vazias e sem sentido.

O DC Goiás (GOIÁS, 2018) ressalta que a internalização das categorias geográficas é fundamental para que os estudantes possam desenvolver sua capacidade de análise das relações antrópicas e naturais, presentes na organização socioespacial do estado de Goiás, do Brasil e do mundo, conforme proposto nas competências específicas de Geografia.

Visando a compreensão dessas categorias e devido a necessidade dos
estudantes de (re)conhecer a formação e características do território goiano,
bem como a importância do estado de Goiás no Brasil e no mundo, foram
acrescidas quarenta e seis novas habilidades, resultantes do
desmembramento de habilidades existentes na BNCC ou, resultantes da
criação de novas habilidades. (GOIÁS, 2018, p. 45 )

Os fundamentos que orientam a seleção de objetos de conhecimento valorizam assim os conceitos como estruturadores do pensamento geográfico que compõem a orientação curricular do DC Goiás. Conceitos de território, paisagem, lugar, região, natureza, entre outros, são valorizados e desdobrados nas unidades temáticas e nos objetivos de aprendizagem que permitem desenvolver de forma didática diversas situações geográficas.

As habilidades articuladas as unidades temáticas e aos objetos de conhecimento poderão servir de referência para o professor de Geografia direcionar a construção de sua proposta de Geografia a ser trabalhada em sala de aula, bem como orientar a organização curricular, além de possibilitar a incorporação de novos temas, considerando os conhecimentos prévios dos seus estudantes, bem como construir com eles os conceitos geográficos necessários para leitura do mundo.

O DC Goiás é um instrumento para orientar o currículo a ser construído e desenvolvido pelo professor de Geografia em Goiás. A partir dele o professor pode ampliar a partir de sua proposta de ensino de Geografia as possibilidades práticas a serem desenvolvidas em sala de aula. As diferentes sequências de conteúdos possibilitadas pelo DC Goiás permitem que o professor desenvolva uma proposta didática para diferentes situações locais, além de possibilitar o estabelecimento de várias conexões entre conteúdos e temas interdisciplinares, superando assim, limites e obstáculos presentes tanto na BNCC quanto no próprio DC Goiás. 


\section{A Geografia na BNCC do Ensino Médio.}

Ter um olhar crítico sobre a BNCC se constitui uma importante tarefa dos professores para a compreensão dos projetos que se colocam em disputa na sociedade e no interior da escola. O desafio é ultrapassar as barreiras e os limites que são postos pela BNCC, espacialmente no Ensino Médio, que empobrece o ensino de determinados componentes curriculares, não explicitando e assegurando a existência dos mesmos a todos os estudantes desta etapa da Educação Básica.

A BNCC do Ensino Médio homologada em dezembro de 2018 (BRASIL, 2018), que, no sentido de orientar a elaboração de itinerários formativos flexíveis, estabelece as competências específicas que devem ser desenvolvidas nas quatro áreas de conhecimento: linguagens e suas tecnologias (7 competências), matemática e suas tecnologias (5 competências), ciências da natureza e suas tecnologias (3 competências) e ciências humanas e sociais aplicadas (6 competências):

Considerando as aprendizagens a ser garantidas aos jovens no Ensino Médio, a BNCC da área de Ciências Humanas e Sociais Aplicadas está organizada de modo a tematizar e problematizar algumas categorias da área, fundamentais à formação dos estudantes: Tempo e Espaço; Territórios e Fronteiras; Indivíduo, Natureza, Sociedade, Cultura e Ética; e Política e Trabalho. Cada uma delas pode ser desdobrada em outras ou ainda analisada à luz das especificidades de cada região brasileira, de seu território, da sua história e da sua cultura. (BRASIL, 2018, p. 562).

Constata-se que há, na BNCC do Ensino Médio, uma ênfase nas categorias da Geografia e na indicação do trabalho do professor por meio dos conceitos que são considerados como basilares para a fundamentação dos estudos dessa ciência. Dentre eles, a BNCC apresenta os conceitos de Território e Fronteira como categorias, cuja utilização na área de Ciências Humanas é bastante ampla.

Durante o Ensino Médio, o estudo dessas categorias, segundo a BNCC do Ensino Médio (BRASIL, 2018), deve possibilitar aos estudantes compreender os processos identitários marcados por territorialidades e fronteiras em históricas disputas de diversas naturezas, assim como deve mobilizar a curiosidade investigativa dos estudantes sobre os seus lugares no mundo, possibilitando a transformação deles e dos lugares em que vivem, além de enunciar aproximações e reconhecer diferenças.

Território é uma categoria usualmente associada a uma porção da superfície terrestre sob domínio de um grupo e suporte para nações, estados, países. É dele que provêm alimento, segurança, identidade e refúgio. Engloba as noções de lugar, região, fronteira e, especialmente, os limites políticos e administrativos de 
cidades, estados e países, sendo, portanto, esquemas abstratos de organização da realidade. Associa-se território também à ideia de poder, jurisdição, administração e soberania, dimensões que expressam a diversidade das relações sociais e permitem juízos analíticos. (BRASIL, 2018, p. 564).

A partir da discussão em torno do conceito de território e fronteira, a BNCC busca interligar as discussões que envolvem as formas de organização do Estado, de governo e do poder que são temáticas enunciadas no Ensino Fundamental e aprofundadas no Ensino Médio, especialmente em sua dimensão formal e como sistemas jurídicos complexos.

Essas temáticas apresentadas de forma bastante ampla na BNCC fornecem alguns elementos capazes de agregar diversos temas de ordem econômica, social, política, cultural e ambiental. Além disso, elas permitem, sobretudo, a discussão dos conceitos veiculados por diferentes sociedades e culturas.

No entanto, Couto (2016), analisando a composição da Geografia na reforma do Ensino Médio, pontua que os objetivos das ciências humanas na BNCC reproduzem o problema da abrangência e da justaposição na definição da área; ou seja, os objetivos não estão expressos de forma clara, de forma que possa ser feita uma delimitação. A articulação conteúdo-método fica fragilizada na medida em que não está claramente estabelecido o papel da História, da Geografia, da Filosofia e da Sociologia na escola. Esse problema não é resolvido, uma vez que os objetivos de aprendizagem de cada componente curricular não estão expressos na BNCC do Ensino Médio.

Em relação ao ensino de Geografia no Ensino Médio, há uma preocupação a longo prazo, pois existe um grande risco de uma diluição dos conhecimentos geográficos pelo enfraquecimento das fronteiras entre as outras disciplinas que compõem as Ciências Humanas. Couto (2016, p. 191) critica tal diluição:

As grandes áreas do conhecimento do ENEM e das Diretrizes Curriculares e, agora, da BNCC, são apenas uma classificação arbitrária dos campos científicos. Não constituem ciência! Não há uma epistemologia das ciências humanas ou naturais, mas das disciplinas e campos científicos que se constituíram a partir do século XVIII e sobretudo no século XIX, através de uma história marcada por diferentes tendências filosóficas e variadas experiências positivas e negativas de integração. A linguagem é inerente ao fazer científico: todas as ciências constituem-se através de e se materializam em linguagens. A geografia nunca se encaixou perfeitamente nas ciências humanas e nem nas ciências naturais, pois aborda temas humanos e naturais, por força da filosofia neo-kantiana na virada do século XIX para o XX. Da mesma forma, o ser humano pode ser interpretado como um sujeito-objeto de estudo da história natural e, simultaneamente, social.

Dessa forma, é necessário enfatizar a crítica à diluição da Geografia dentro do itinerário de Ciências Humanas e Sociais Aplicadas, uma vez que a constituição da Geografia Escolar como um componente do currículo e seu ensino em todas as séries do Ensino Médio é 
caracterizada pela possibilidade de que os estudantes percebam a singularidade de sua vida e reconheçam sua identidade e o seu pertencimento ao mundo atual.

Callai (2013) pontua que a Geografia é uma matéria curricular que possibilita compreender o mundo e a sociedade em que vivemos, reconhecendo a espacialidade dos fenômenos sociais. Por meio da leitura do espaço, o importante é ler o mundo, o que significa compreender aquelas informações que estão no cotidiano das pessoas, entendendo a expressão das formas nas paisagens. A Geografia se constitui como uma importante ferramenta intelectual para entender esse mundo.

Falta à BNCC do Ensino Médio explicitar o que se ensina em Geografia, como, por que e para quem ela é ensinada, e qual é o corpus dessa disciplina - algo que Callai (2013) aponta como a demarcação necessária para que se possa dizer isso é Geografia. Ao olhar para o documento homologado para o Ensino Médio, é perceptível a falta da Geografia como um campo do conhecimento autônomo e do seu significado como conteúdo escolar. Nota-se uma perda da identidade da Geografia Escolar e um esvaziamento da abordagem científica específica desse componente curricular em detrimento da sua inserção no itinerário formativo de Ciências Humanas e Sociais Aplicadas.

\section{Considerações Finais}

A educação geográfica exige, sobretudo, a valorização das vivências cotidianas do estudante, desvelando suas práticas espaciais e as perspectivas de leituras do espaço geográfico, a partir da interpretação das paisagens e da compreensão dos conceitos geográficos. A Geografia apresentada no DC Goiás - Anos Finais do Ensino Fundamental - traz importantes possibilidades de ampliação das escalas de entendimento do mundo por meio dos estudos regionais, abordando problemáticas internacionais e problematizando os cenários que o mundo contemporâneo apresenta, tais como: os contextos raciais e o acirramento das desigualdades regionais, as migrações e os conflitos étnicos e por recursos naturais, os desastres naturais e a divisão desigual das riquezas, o papel que alguns países assumem na produção econômica mundial, as guerras etc.

Compreende-se que o DC Goiás para o Ensino Fundamental trabalha com a proposta de desenvolvimento de competências e habilidades no sentido de favorecer a formação integral do estudante, proporcionando-lhe a compreensão do espaço local e suas inter-relações com o global, permitindo-lhe o reconhecimento e a valorização dos diferentes saberes como também favorecendo a construção de uma atitude responsável diante da natureza e consciente de suas responsabilidades e direitos. 
Frente a críticas postas a BNCC, como as apontadas por Cury, Reis e Zanardi (2018) e Camilo Costa, Rodrigues e Stribel (2019) destacando os indicativos prescritivos de como deve ser operada a Geografia nas escolas (ao propor o afastamento da empiria microcontextual, das experiências da escala do cotidiano em favor do domínio de conceitos e generalizações), ressalta-se aqui a importância do trabalho a ser desenvolvido pelo professor de Geografia no desenvolvimento das habilidades apresentadas no DC Goiás (e ampliadas a partir da BNCC).

É no trabalho do professor de Geografia que limites e obstáculos presentes nesses documentos curriculares podem ser superados. Nesse trabalho didático desenvolve-se, organiza-se e problematiza-se temas e conteúdos para investigação e ensino que são desenvolvidos em sala de aula. O desenvolvimento do pensamento geográfico pelos estudantes é a referência para o trabalho do professor, conforme destaca Cavalcanti (2019) é a produção de conhecimentos significativos para a vida cotidiana dos estudantes, para a participação na vida social com qualidade, consciência e responsabilidade cidadãs.

Para concluir é necessário destacar uma preocupação em relação ao processo de construção da BNCC do Ensino Médio. Desde a primeira versão, notou-se um emaranhado de transformações que não caminharam para o desenvolvimento de uma base que contribuísse para o trabalho do professor em sala de aula. Ao finalizar a análise do documento da parte referente ao Ensino Médio, chega-se as seguintes indagações: Existirá outro documento que instrumentalizará os conteúdos (e daí contemplem os conceitos) a serem trabalhados nas escolas? O DC Goiás para o ensino médio trará essas possibilidades para o trabalho do professor?

Entende-se que há sim inconsistências e fragilidades que precisam ser compreendidas, analisadas e debatidas no conjunto da BNCC que será implementada no Ensino Médio. Existe uma necessidade premente de considerar a inadequação das formulações apresentadas quanto às dimensões formativas e aos objetivos de aprendizagens. Ao observar as competências e as habilidades da BNCC para o Ensino Médio dentro do itinerário de Ciências Humanas e Sociais, percebe-se que falta uma clareza necessária para o desenvolvimento de um ensino de Geografia com qualidade para essa etapa da educação básica.

Para os professores de Geografia do Ensino Médio, materializa-se o desafio de ser capaz de construir o pensamento geográfico e conseguir perceber como encaminhar o ensino a partir dos instrumentos que são disponibilizados pelo mundo em que estamos vivendo. Callai (2013) destaca que, ao produzir significados para os conceitos específicos ou fundamentais da Geografia, passa-se a ter ferramentas intelectuais para avançar nesse conhecimento. O desafio, nesse sentido, é saber qual é o grupo de conceitos que permite ao sujeito pensar sobre determinado assunto e desenvolver o pensamento geográfico. 


\section{Referências}

BRASIL. Ministério da Educação. Base Nacional Comum Curricular - Versão Final. Brasília: MEC, 2018. Disponível em: <http://basenacionalcomum.mec.gov.br>. Acesso em: 29/02/2019.

CALLAI, H. C. A formação do profissional da geografia: o professor. Ijuí: Ed. Unijuí, 2013.

CAMILO COSTA, Hugo Heleno; RODRIGUES, Phelipe Florez; STRIBEL, Guilherme Pereira. Teoria curricular e Geografia: convites à reflexão sobre a BNCC. Revista Brasileira de Educação em Geografia, Campinas, v. 9, n. 17, p. 86-108, jan./jun., 2019. Disponível em: <http://www.revistaedugeo.com.br/ojs/index.php/revistaedugeo/article/view/578>.

Acesso em: 21/10/2019.

CASTELLAR, Sonia Maria Vanzella. Raciocínio geográfico e a teoria do reconhecimento na formação do professor de geografia. Revista Signos Geográficos: Boletim NEPEG de Ensino de Geografia. Goiânia, n. 1, 2019. Disponível em: <https://www.revistas.ufg.br/signos/article/view/59197 >. Acesso em: 16/11/2019.

CAVALCANTI, Lana de Souza. Pensarpela Geografia: ensino e relevância social. Goiânia: C\&A Alfa Comunicação, 2019.

COUTO, M. A. C. Base Nacional Comum Curricular - BNCC. Componente curricular: geografia. Revista da Associação Nacional de Pós-graduação e Pesquisa em Geografia (Anpege). p.183-203, v.12, n.19, jul-dez.2016. Disponível em: <http://ojs.ufgd.edu.br/index.php/anpege/article/view/6379>. Acesso em: 22/01/2018. DOI: https://doi.org/10.5418/ra2016.1219.0008

CURY, C. R. J.; REIS, M.; ZANARDI, T. A. C. Base Nacional Comum Curricular: dilemas e perspectivas. São Paulo: Cortez, 2018.

GOIÁS. Conselho Estadual de Educação. Resolução CEE/CP no 08, de 06 de dezembro de 2018. Aprova o Documento Curricular da Educação Infantil e Ensino Fundamental para o sistema educativo de Goiás. Goiânia: CEE, 2018. Disponível em: <cee.go.gov.br/wp-content/uploads/2019/08/DocumentoCurricular-para-Goi\%C3\%A 1s.pdf>. Acesso em: 22/02/2019.

LOPES, A. C. L. Por um currículo sem fundamentos... In: WELLER, Wivian; GAUCHE Ricardo (orgs.). Ensino Médio em debate: currículo, avaliação e formação integral. Brasília: Editora Universidade de Brasília, 2017, p. 25-55.

SANTOS, Milton. O papel ativo da Geografia: um manifesto. Território. Rio de Janeiro, n.9, p.103, jul./dez. 2000. Disponível em: $<$ http://www.laget.eco.br/index.php?option=com_wrapper\&view=wrapper\&Itemid=6>.

Acesso em: 16/01/2018 